\title{
Periódica Eletrânica

\section{POLÍTICAS PÚBLICAS DE GESTÃO AMBIENTAL E SUSTENTABILIDADE: UM ESTUDO DE CASO DO MUNICÍPIO DE RIBEIRÃO PRETO, SP}

\author{
Carmino Hayashi ${ }^{1}$ \\ Leonardo Henrique de Almeida e Silva ${ }^{2}$
}

\begin{abstract}
RESUMO
Este trabalho objetivou o estudo de caso do município de Ribeirão Preto-SP, onde foram analisados alguns aspectos de políticas públicas e questões ambientais - gestão ambiental e sustentabilidade. Os dados foram obtidos através de levantamentos bibliográficos e pesquisas em arquivos públicos e privados. Em termos de instrumentos de políticas públicas, Ribeirão conta com a Secretaria de Meio Ambiente, a Lei Orgânica Municipal, o Código do Meio Ambiente, o Conselho Municipal de Defesa do Meio Ambiente, além do Plano Diretor, Lei de Uso e Ocupação do Solo, Plano de Mobilidade e Plano de Saneamento; complementadas pelas diretrizes do Plano Plurianual, Agenda 21 - Ribeirão Preto e Comitê de Bacias Hidrográficas - Rio Pardo, o que determina o perfil atual de Ribeirão Preto no tocante a Gestão Ambiental e Sustentabilidade. Resumidamente, Ribeirão Preto apresenta em seu organograma administrativo todas as necessidades para um eficiente desempenho em termos de Gestão Ambiental, embora na prática tal processo não ocorra em função de problemas diversos. Podemos concluir ainda, que não há sintonia entre o Executivo e o Legislativo e tampouco com os outros órgãos colegiados, agravados por um Legislativo relativamente submisso, com poucas proposituras e eficiência fiscalizadora, além da morosidade, ao mesmo tempo em que se identifica uma gestão que pouco atende as recomendações e deliberações da sociedade e dos Conselhos afetos às questões ambientais.
\end{abstract}

PALAVRAS CHAVE: Gestão ambiental, Políticas públicas ambientais, Meio ambiente, Ribeirão Preto.

\section{PUBLIC POLICIES OF ENVIRONMENTAL MANAGEMENT AND SUSTAINABILITY: A CASE STUDY OF THE CITY OF RIBEIRÃO PRETO, SP}

\section{SUMMARY}

This paper aimed to the case study of the city of Ribeirão Preto-SP, which analyzed some aspects of public policies and environmental issues - environmental management and sustainability. The data were obtained through bibliographic surveys and research in public and private archives. In terms of instruments of public policies, Ribeirão Preto relies on the Secretariat of the Environment, the Organic Municipal Law, the Code of the Environment, the Municipal Council for the Defense of the Environmental, in addition to the Master Plan, Law of Soil Use and Soil Occupation, Mobility Plan and

\footnotetext{
${ }^{1}$ Graduação em Ciências Biológicas/USP-RP, Bacharel em Administração Pública/UFSJ e Doutor em Ciências (Ecologia e Recursos Naturais) - UFSCar, E-mail: hayashi@terra.com.br

${ }_{2}^{2}$ Professor do IPTAN, Professor do IF/ Câmpus São João del-Rei, Graduação em Administração/FCCAMS, Graduação em Ciências Econômicas/UFJF e Mestre em Economia/UFES, E-mail: leonardo.henrique@ifsudestemg.edu.br
} 
Sanitation Plan; complemented by the guidelines of the Multi Annual Plan, Agenda 21-Ribeirão Preto and Watershed Committee - Rio Pardo, which determines the current profile of Ribeirão Preto in respect of Environmental Management and Sustainability. Briefly, Ribeirão Preto presents in your administrative organization all administrative requirements for an efficient Environmental Management performance, although in practice this process does not occur due to various problems. We can also conclude, that there is not harmony between the Executive and the Legislature, nor with the other collegiate organs, compounded by a relatively submissive legislature, with few propositions and supervision efficiency, in addition to slow, at the same time when it turns a management that no meets the recommendations and deliberations of the society and of the Board affects environmental issues.

KEYWORDS: Environmental Management, Environmental Public Policies, Environment, Ribeirão Preto.

\section{POLÍTICAS PÚBLICAS DE GESTIÓN AMBIENTAL Y SOSTENIBILIDAD: UN ESTUDIO DE CASO DE LA CIUDAD DE RIBEIRÃO PRETO, SP}

\section{RESUMEN}

Este trabajo tuvo como objetivo el estudio de caso de la ciudad de Ribeirão Preto-SP, donde se analizaron algunos aspectos de la política pública y el cuestiones ambientales - la gestión ambiental y la sostenibilidad. Los datos fueron obtenidos a través de encuestas de la literatura y la investigación en archivos públicos y privados. En términos de instrumentos de política, Ribeirão Preto tiene la Secretaría de Medio Ambiente, la Ley Orgánica Municipal, el Código del Medio Ambiente, el Consejo Municipal para la Defensa del Medio Ambiente, además del Plan Maestro, Ley de Uso y Ocupación del Suelo, Plan de Movilidad y el Plan de Saneamiento; complementado con las directrices del Plan Plurianual, el Programa 21 - Ribeirão Preto y Comité de Cuencas de los Ríos - Rio Pardo, que determina el perfil actual de Ribeirão Preto, en relación a la Gestión Ambiental y Sostenibilidad. Brevemente Ribeirão Preto presenta en su organigrama administrativo todas las necesidades para el desempeño eficiente en términos de Gestión Ambiental, aunque en la práctica, este proceso no se produce en función de diversos problemas. También podemos concluir que no hay armonía entre el Poder Ejecutivo y el Poder Legislativo, ni con los otros órganos colegiados, agravadas por una legislatura relativamente sumisa, con pocas proposiciones y eficiencia de supervisión, además de muy lento, y al mismo tiempo que identifica una gestión que poco cumple con las recomendaciones y deliberaciones de la sociedad y los Consejos afectos a las cuestiones ambientales.

PALABRAS CLAVE: Gestión Ambiental, Políticas Públicas Ambientales, Medio Ambiente, Ribeirão Preto.

\section{INTRODUÇÃO}

O município de Ribeirão Preto - SP até por volta da metade do século XX era conhecido no passado como a "Capital do Café", quando em meados da década de 80 do mesmo século passou a ser considerada a "Califórnia Brasileira", e atualmente a denominam de "Capital Brasileira do Agronegócio" conforme INEPAD (2013).

Conforme dados oficiais da PMRP (2014a), o município localiza-se em um planalto na região Norte/Nordeste do Estado de São Paulo, com relevo plano, pequenos declives e ondulações naturais. Possui solo característico denominado de 
terra roxa, oriundas de alterações de rochas vulcânicas (Formação Serra Geral) e arenitos (Formação Botucatu), consideradas terras boas e férteis. O clima é tipicamente tropical úmido, com verão chuvoso e inverno seco, sendo que no verão a temperatura máxima média mensal atinge em torno $30^{\circ} \mathrm{C}$, com índice pluviométrico mensal superior a $200 \mathrm{~mm}$ de chuva e umidade relativa do ar em torno de $80 \%$. Por outro lado no inverno apresenta uma temperatura mínima com média mensal em torno de $13^{\circ} \mathrm{C}$ e precipitação média entre $20-30 \mathrm{~mm}$ e umidade relativa do ar por volta de $60 \%$.

Situado numa altitude de $546 \mathrm{~m}$, o município apresenta uma área de $651,366 \mathrm{~km}^{2}$ e uma população estimada de 650.114 hab. conforme IBGE (2014), com uma densidade demográfica de 929,5 habitantes $/ \mathrm{km}^{2}$. Em termos geográficos apresenta um relevo de planalto, com clima tropical de altitude, temperatura média anual de $26^{\circ} \mathrm{C}$, índice pluviométrico de $1430 \mathrm{~mm}$, vegetação do tipo Mata Atlântica em pouca quantidade, e tendo como principais rios o Pardo e Ribeirão Preto (IBGE, 2014).

Em relação aos dados econômicos e sociais apresenta um Produto Interno Bruto (PIB) de $R \$ 18,7$ bilhões (2011), Renda Per Capita de $R \$ 1.314,04$ (2010), Índice de Desenvolvimento Humano (IDH) de 0,800 (2010), tendo como principais atividades econômicas a indústria, comércio e serviços, segundo os dados do IBGE (2014). Nos dias atuais é considerado uma dos mais importantes municípios do interior paulistano, tendo um orçamento previsto para o ano de 2015 em torno de 2,53 bilhões de reais conforme proposta orçamentária da PMRP (2014a). No ano de 2012, conforme os dados do Ministério do Desenvolvimento Indústria e Comércio MDIC (2012), Ribeirão Preto teve um saldo na balança comercial de US\$14,4 bilhões, sendo que US $\$ 181,3$ milhões representavam exportações e US $\$ 166,7$ milhões em importações.

Considerando que o município é a unidade governamental mais próxima da população, o processo participativo da população deve superar a simples representação nos Conselhos, pois existem diversos outros meios pelas quais os cidadãos podem monitorar e participar ativamente da gestão ambiental local em conjunto com o poder público, na elaboração de diretrizes e cumprimento de uma política municipal de proteção ao meio ambiente com sustentabilidade. De acordo com Rodrigues et al. (2012), sob o ponto de vista normativo, o município é 
considerado a denominação geopolítica do espaço na qual a população faz parte e sobre o qual suas ações podem incidir diretamente, em todas as suas atuações, construindo a sua territorialidade, inclusive nas questöes ambientais. Neste enfoque, Banunas (2003) e Maglio (2000) expressam o que é consenso sobre a gestão ambiental, a de que os princípios globalmente estabelecidos, incorporados pelas nações e normatizados em seus estados, identificam nos municípios o locus de sua aplicação, pois é no poder municipal que encontramos a possibilidade de adequá-los às suas especificidades para uma eficiente qualidade ambiental.

Um dos grandes desafios do desenvolvimento sustentável urbano é a da busca de novos modelos de políticas públicas ambientais que conjuguem esforços de desenvolvimento econômico com as ações equilibradas de proteção ao meio ambiente e bem-estar social (ROSSETTO, 2012), diminuindo a taxa de degradação do meio ambiente, repensando a gestão, o planejamento, as ações públicas e práticas de governabilidade do município em consonância com o meio ambiente.

\section{OBJETIVOS E METODOLOGIA DO ESTUDO DE CASO}

Este projeto objetivou especificamente levantar dados sobre o organograma administrativo municipal e de órgãos e legislações ambientais, para o estudo de caso do município de Ribeirão Preto-SP, onde foram abordados, analisados e discutidos alguns aspectos de políticas públicas e questões ambientais - gestão ambiental e sustentabilidade; cujos dados foram obtidos por meio de levantamentos bibliográficos atualizados e pesquisas em arquivos públicos e privados. Constituiu-se numa análise onde foram identificados e analisados alguns aspectos pertinentes ao histórico, gestão e políticas públicas do município atreladas à manutenção e prevenção do meio ambiente com sustentabilidade (gestão ambiental sustentável), resultando ao final em algumas considerações analíticas e proposituras sobre melhorias e avanços na área.

\section{DAdOS SOBRE POLÍtICAS PÚBLICAS, GESTÃo AMBIENTAL E SUSTENTABILIDADE NO MUNICÍPIO DE RIBEIRÃO PRETO, SP}


A Secretaria do Meio Ambiente, em sua organização administrativa, conforme a PMRP (2014b), constitui-se dos seguintes órgãos: Gabinete do Secretário (Seção de Gerenciamento de Pessoal e Seção de Gerenciamento Administrativo e de Custo Operacional); Departamento de Gestão Ambiental (Divisão de Planejamento e Educação Ambiental; Divisão de Licenciamento e Controle Ambiental; Divisão de Áreas Verdes e Divisão de Parques Públicos). A atual Secretaria do Meio Ambiente, além dos órgãos especificados acima agrega ainda o Fundo Pró-Meio Ambiente, tendo sido criada por meio da Lei 2.257/2008 de 16/04/2008.

As responsabilidades pelas políticas ambientais sempre ficaram sob os encargos dos órgãos estaduais e federais, sendo que em raríssimas situações os municípios chamaram para si esta importantíssima atividade, exceto no cuidado de algumas praças centrais. Entretanto a partir Resolução n.ำ 237/97 do CONAMA Conselho Nacional de Meio Ambiente, uma série de atribuições passaram a ser de competência municipal, tais como a avaliação dos impactos ambientais locais provocados pelos empreendimentos urbanos, coordenação de ações e desenvolvimento em conjunto com a comunidade, discussões ambientais na busca de normativas que evitem a degradação ambiental e recuperem áreas afetadas. Para tanto a existência de uma secretaria que tenha estas responsabilidades é fundamental para estabelecer um desenvolvimento sustentável, priorizando conceitos e critérios de equilíbrio socioambiental.

Em sua Lei Orgânica Municipal de Ribeirão Preto, conforme atualização efetuada pela Emenda oㅡ 01, de 26 de abril de 2013, é encontrado em seu Capítulo III - Da política de desenvolvimento urbano e rural, Artigo 151 que "A política de desenvolvimento urbano, executada pelo Poder Público Municipal, conforme diretrizes gerais fixadas em lei têm por objetivo ordenar o pleno desenvolvimento das funções sociais da cidade e garantir o bem-estar de seus habitantes". Ainda nesta mesma Lei Orgânica, encontraremos em seu Capítulo IV - Do Meio Ambiente, dos Recursos Naturais e do Saneamento, os artigos 156 a 160 que trata dos direitos, limites de competência, ações, planos e cumprimentos das questões ambientais. Além do Capítulo IV - Do Meio Ambiente, dos Recursos Naturais e do Saneamento da Lei Orgânica do Município de Ribeirão Preto, que contém em seus Artigos $157^{\circ}$ a $160^{\circ}$ e respectivos parágrafos, algumas normativas sobre as 


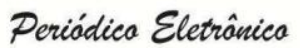 \\ Fórum Ambiental}

da Alta Paulista
Volume 11, Número 07, 2015

Politicas Públicas e a Proteção do Meio Ambiente

questões ambientais acima elencadas, somente vamos encontrar ainda outras referências sobre a temática em seu Capítulo II - Da Competência, em seu Artigo 5응 que determina a competência ao município de Ribeirão Preto, em comum com a União e com o Estado, observados as normas de cooperação fixadas em lei complementar federal proteger o meio ambiente e combater a poluição em qualquer de suas formas (VI) e preservar as florestas, a fauna e a flora (VII).

Ribeirão Preto conta ainda em termos de planejamento, implementação, gestão ambiental, sustentabilidade e controle ambiental com um Código do Meio Ambiente, que dispõe sobre os sistemas de administração da qualidade, proteção, controle e desenvolvimento do meio ambiente, e uso adequado dos recursos naturais; os instrumentos da política ambiental, estabelecendo normas gerais para a administração da qualidade ambiental do município de Ribeirão Preto/SP, conforme o seu Artigo $1^{\circ}$ do Projeto de Lei Complementar no 181/2001, de autoria do Executivo Municipal e aprovado pela Câmara Municipal. Esta Lei que institui o Código Municipal do Meio Ambiente "estabelece as bases normativas da política municipal do meio ambiente, cria o Sistema Municipal de Administração da Qualidade, Proteção, Controle e Desenvolvimento do Meio Ambiente, e Uso Adequado dos Recursos Naturais - SIMA, os instrumentos da política ambiental e estabelece normas para a administração, proteção e controle dos recursos ambientais e da qualidade do meio ambiente do Município de Ribeirão Preto". Este projeto de LC no 181/2001, na realidade vem de encontro a outro projeto de Lei Complementar anteriormente aprovada ( $n^{\circ}$ 501, de 31/10/95) em que já se observava uma crescente preocupação com as questões ambientais, uma vez que ela precede a Res. n. 237/97 - CONAMA. Na esteira destas Leis Complementares, foi instituído o Código Municipal do Meio Ambiente, que estabeleceu as bases normativas da política municipal do meio ambiente do Município de Ribeirão Preto/SP.

O Conselho Municipal de Defesa do Meio Ambiente (COMDEMA) foi criado pela Lei Complementar $\underline{n^{\circ} 287 \text { de 29/11/93 }}$, possui entre outras diversas atribuições, sugerir e colaborar na elaboração de leis ambientais, atuar na fiscalização do fiel cumprimento das leis ambientais, receber denúncias de agressões ao meio ambiente; deliberar sobre o uso, ocupação e parcelamento do solo em áreas de interesse ambiental; propor e colaborar com programas de educação ambiental. 
Ressalve-se que em conformidade com a Lei Orgânica do Município em seu artigo 157, parágrafo único, é um órgão de caráter colegiado, consultivo e deliberativo encarregado de assessorar o poder público em assuntos referentes à proteção, conservação e melhoria do meio ambiente, conforme PMRP (2013). É interessante notar que a instalação destes conselhos, foi proposta a partir da Constituição Federal de 1988, buscando o fortalecimento da autonomia municipal, conforme IBGE (2009), pois confere ao mesmo, autoridade consultiva e/ou deliberativa e/ou normativa e/ou fiscalizadora e de assessoramento do poder executivo municipal, em relação às questões ambientais, formatando uma nova relação entre o Estado e a sociedade e, institucionalizando a participação de diversos segmentos da sociedade civil organizada, implicando numa nova cultura social participativa.

A Secretaria Municipal do Meio Ambiente mantém diversas parcerias com instituições da cidade, tais como o Coletivo Educador Ipê Roxo que trabalha com políticas públicas de formação de educadores ambientais, além de desenvolver cursos como o de Mapeamento, Diagnóstico e Intervenção Sócio Ambiental, em parceria com a Agência USP de Inovação, o grupo de estudos Gira - Recicla do Centro Universitário Barão de Mauá e Centro de Formação Sócio Agrícola Dom Helder Câmara, entre outras (PMRP, 2008). O projeto denominado Cooperativa Mãos Dadas, objetiva promover a inclusão social e econômica dos catadores de recicláveis, que teve início em 2005, através da iniciativa e disponibilidade de alguns profissionais e poucos catadores, sendo que atualmente conta com os mais diversificados grupos de parcerias do setor público e privado no município, originando posteriormente em 2008 a criação da Cooperativa de Agentes Ambientais Mãos Dadas (PMRP, 2008). Outro programa da Secretaria refere-se ao Programa Criança Ecológica, criado em março de 2009, em parceria com o Governo do Estado - Secretaria Estadual de Meio Ambiente, objetivando sensibilizar e despertar nas crianças atitudes que contribuam para a melhoria da qualidade de vida e do meio ambiente, tendo algumas escolas municipais como unidade piloto do programa e envolvendo espaços específicos como a ETE (Estação de Tratamento de Esgotos) trabalhando a agenda água e poluição, o Parque Municipal "Prefeito Luiz Roberto Jábali - Curupira" com o tema poluição, aquecimento global e solo, o Parque Ecológico "Ângelo Rinaldi - Horto Municipal” com a agenda flora e o Bosque e Zoológico Municipal vinculado à temática fauna (PMRP, 2008). 
O município possui diversos parques municipais e áreas verdes que são abertos gratuitamente à visitação pública em horários estabelecidos pelas normas de um, segundo a PMRP (2008). Os parques e reservas são as seguintes: Parque Morro de São Bento, Bosque Zoológico Fábio Barreto, Jardim Japonês, Parque Prefeito Luiz Roberto Jábali (Parque Curupira), Parque Dr. Luiz Carlos Raya, Parque Maurílio Biagi, Parque Roberto de Melo Genaro, Parque Tom Jobim, Parque Ecológico Ângelo Rinaldi (Horto Municipal Florestal) e Estação Ecológica de Ribeirão Preto (Mata Santa Teresa). Bosque e Zoológico Fábio de Sá Barreto representa uma das mais antigas áreas verdes do município, sendo conhecida anteriormente como Bosque Municipal, sendo posteriormente enquadrado também como Zoológico. Anteriormente até por volta da década de 70 o antigo Bosque Municipal possuía alem da exposição de diversos animais de nossa fauna, um belo orquidário com muitas variedades e um aquário com espécies ornamentais e outros peixes de nossos rios. Estes dois atrativos foram extintos e somente agora está sendo construído um novo aquário para visitação pública (PMRP, 2008). No tocante as atividades que envolvam a propagação de conhecimentos e aprendizagem na área de educação ambiental existem as atividades do Setor de Educação Ambiental, do Programa de Estágio e Visitas Monitoradas.

\section{ANÁLISE E DISCUSSÃO DO ESTUDO DE CASO}

Conforme especifica Dias (2009), a gestão pública ambiental conduzida nos municípios, tanto pela sua proximidade com os cidadãos como pelas fragilidades dos processos ecológicos, deve envolver todas as dificuldades inerentes aos problemas ambientais, considerando-os prioritários, e em consequência definir algumas medidas como parte instrumental que proporcione um suporte para tomadas de decisões de preservação ou corretivas. Hoje, inúmeros municípios tem se posicionado tomando medidas preventivas e priorizando salvaguardas relacionadas às questões ambientais, buscando a sustentabilidade local, assim como ferramentas que as direcionem para um maior desenvolvimento econômico, social e ambiental sobre a égide do desenvolvimento sustentável.

É responsabilidade do governo municipal, segundo Ribeiro et. al. (1998) as atribuições de tomar medidas preventivas e/ou solucionar os problemas ambientais 
em áreas urbanas, assim como cabe também ao governo municipal à aprovação e aplicação de normas de controle urbano e ambiental. Estas responsabilidades são advindas de legislações superiores que disponibilizam aos municípios os instrumentos legais de gestão ambiental, que possuem autonomia para criar suas próprias leis municipais, desde que não sejam conflitantes com as legislações estaduais e federais relacionadas ao tema.

Entre os diversos instrumentos de Planejamento Ambiental e Sustentabilidade Municipal, de acordo com Little (2003), podemos incluir uma infinidade de programas, projetos, leis municipais que normatizem e norteiem para um desenvolvimento sustentável no município, tais como o Plano Diretor, Lei de Uso e Ocupação do Solo, Plano de Mobilidade e Plano de Saneamento, mas que em Ribeirão Preto estas regulamentações estão em processo de elaboração ou aprovação há anos. Conforme dados da PMRP (1995) e PMRP (2013), o Plano Diretor deve ser revisado a cada 10 anos, entretanto a última revisão em Ribeirão Preto foi elaborada em 2003, portanto está com 11 anos de atraso, sendo que o texto revisado permanece na Câmara Municipal desde o final de Outubro/2014. A Lei de Uso e Ocupação do Solo, cuja revisão foi aprovada em 2012, está suspensa, pois foi considerado inconstitucional pelo Tribunal de Justiça de São Paulo (TJ/SP) e até mesmo o projeto substitutivo apresenta aspectos de irregularidades inconstitucionais, permanecendo junto a Secretaria de Negócios Jurídicos, que analisa as medidas jurídicas a serem tomadas estando, portanto em situação de indefinição. O Plano de Mobilidade Urbana, assim como o Plano de Saneamento Básico está em elaboração desde 2011, mesmo tendo neste período recebido verbas do governo federal, segundo informações do executivo/legislativo os planos estavam em fase de conclusão. Segundo o Ministério das Cidades, a Lei Federal 12.587/12, determina que estados e municípios que queiram solicitar recursos federais na área de mobilidade urbana, deverão obrigatoriamente possuir seus Planos de mobilidade aprovados. Para o Plano de Mobilidade, o executivo alega dispor de um prazo até Dezembro de 2014, enquanto o Plano de Saneamento deve ser concluído até o próximo ano (2015).

Segundo Little (2003), o Plano Diretor, assim como os outros planos após aprovação, torna-se um instrumento fundamental da política de desenvolvimento e de expansão urbana municipal, uma vez que sua elaboração leva em conta vários aspectos como um planejamento dinâmico e articulado com políticas de 
desenvolvimento, definindo as prioridades de ações temporais e espaciais, para composição do modelo de gestão integrada do município. Dentro deste contexto, devemos considerar estes planos como sendo um instrumento de gestão territorial urbana, que corresponde também a um eficiente instrumento de gestão ambiental, talvez a mais importante, sobretudo pelo fato da inexistência de uma tradição de políticas públicas ambientais em nível municipal no Brasil, conforme Carvalho e Braga (2001).

Quanto ao parcelamento do solo urbano, disciplina-se pela Lei Federal ํㅡㄴ 6.766/1979, com suas alterações, mas as normas específicas ficam sob a competência do Município, que deve manifestar-se conforme as exigências locais, argumento reforçado por Gonçalves (2009), assim como em referência ao Código de Obras, que possibilita a Administração Municipal, o exercício do controle e a fiscalização dos espaços edificados e seu entorno, garantindo as condições ambientais de segurança, salubridade e bem estar dos cidadãos. Complementarmente, conforme dispõe Carvalho (2001), o conceito do zoneamento (Lei de zoneamento) "é o instrumento legal de que dispõe o Poder Público para controlar o uso da terra, as densidades de população, a localização, a dimensão, o volume dos edifícios e seus usos específicos, em prol do bem-estar social".

De forma mais abrangente, também o Plano Plurianual, conforme Little (2003) deve refletir as prioridades sociais e ambientais da sociedade, o que implica entender que estas prioridades devem ser destacadas no conjunto de outros projetos para contar com o respaldo dos setores responsáveis na esfera municipal, dada a importância que o processo ambiental representa dentro do PPA. Ainda de acordo com Gonçalves (2009), consta no artigo 165 da Constituição Federal de 1988, que “... o Governo programe ação que oriente os investimentos e outros compromissos no decorrer da sua gestão... elaborando um plano que vai vigorar nos próximos três anos de mandato", donde podemos afirmar que é no Plano Plurianual que vamos encontrar os objetivos estratégicos municipais para promover o desenvolvimento sustentável.

O Programa Agenda 21 - Ribeirão Preto foi criado pelo Projeto de Lei no 895/98, mas promulgada somente no ano de 2.000, oito anos após a Rio-92 que foi sua propositora, onde preconizava a sistematização de um plano de ações com o objetivo de alcançar o desenvolvimento sustentável. Em seu primeiro artigo 
especifica: "Artigo 1ํ - Fica, através da presente lei, criado o Programa Agenda 21 Ribeirão Preto, com a finalidade de normatizar, facilitar e integrar as ações necessárias à implementação da Agenda 21 da Conferência das Nações Unidas sobre Meio Ambiente e Desenvolvimento - Rio/92, no âmbito do município de Ribeirão Preto" (PMRP, 1998). Considerando-se as análises sobre o Plano Diretor, verificamos que a proposta de envolvimento dos governos municipais, num plano de ação para a preservação ambiental, objetivando proteção ambiental, sustentabilidade urbana, justiça social e eficiência econômica, através de parcerias entre autoridades locais, comunidade e outros setores para implementá-las, conforme a Agenda 21, Mattei (2010); o município de Ribeirão fica excluído destas pretensões, embora haja raríssimas exceções, principalmente oriundas da iniciativa privada e do terceiro setor.

Em relação aos Conselhos Municipais de Meio Ambiente, Carvalho et al. (2005) argumentam que o diferencial destes Conselhos vai depender principalmente do grau de democratização alcançado pelos grupos que o compõem e da frequência com que discutem seus problemas deliberam seus pareceres, embora cientes que as deliberações emitidas pelo Conselho estarão a mercê de serem efetivadas, dependendo, sobretudo da capacidade de articulação e do peso político que a entidade angariou na administração local e na sociedade. No tocante as atividades do COMDEMA no município de Ribeirão Preto (PMRP, 1993), e de acordo com o que consta nas páginas da mesma, suas atividades mostram-se pertinentes e com encaminhamentos dentro das propostas e objetivos que as norteiam como um Conselho Ambiental, embora haja no meu entendimento baixa participação popular. Considere-se que muitos municípios brasileiros não possuem formalmente um Conselho Municipal, assim como quando as têm, poucos se interessam em discutir políticas públicas municipais de cunho ambiental, o que reforça um baixo nível de conhecimento das questões ambientais, conforme argumenta Little (2003).

Visando políticas públicas ambientais municipais, Carvalho et al., (2005) especifica que os municípios podem criar um fundo especial (Fundo Municipal do Meio Ambiente), com o objetivo de apoiar projetos de caráter sustentável e uso racional dos recursos naturais dentro de suas divisas, ou para à manutenção e recuperação da qualidade ambiental, conforme preconiza a Política Nacional do Meio Ambiente. Entretanto, estes tipos de políticas empreendedoras envolvendo 
municípios de uma macrorregião como Ribeirão Preto, não têm surtido efeitos, exceto como práticas políticas de alguns executivos ou legisladores em diferentes níveis.

Da mesma forma, de acordo com Gonçalves (2009) um consórcio público também pode ser operacionalizado, com o intuito de agregar técnicos especializados e aspectos financeiros, entre vários municípios que isoladamente não teriam condições de viabilizá-los. Como estes problemas ambientais apresentam-se muito complexos e demandam recursos de grande monta, extrapolando os limites municipais; os municípios regionais devem equacionar-se e organizarem-se para o enfrentamento em conjunto destes problemas na forma de consórcios municipais em busca de recursos estaduais e federais para as resoluções de seus problemas ambientais. Exemplificando, os Comitês de Bacias Hidrográficas na região de Ribeirão Preto, conforme consta no Decreto Estadual № 39.116/98, representado pelo Comitê de Gerenciamento da Bacia Hidrográfica do Rio Pardo (São Paulo, 1998), de certa forma já traduz uma formação de rede ou consórcio, que buscam ações preservacionistas relacionadas à qualidade das águas, independente dos limites políticos ou geográficos municipais, tendo em vista as extensões intermunicipais de nossos rios, conforme cita Schenini e Nascimento (2002). Em relação a estas demandas ambientais, este tipo de políticas ambientais relacionadas às questões da água de superfície a região tem apresentado resultados satisfatórios.

Existem várias outras estruturas administrativas e legislações relacionadas às questões de gestão ambiental e sustentabilidade que deveriam ser abordadas, entretanto as mais importantes foram apresentadas e discutidas como o Plano Diretor, Lei de Uso e Ocupação do Solo, Plano de Mobilidade e Plano de Saneamento; além das diretrizes do Plano Plurianual, Conselho Municipal de Meio Ambiente, Agenda 21, Comitê de Bacias Hidrográficas e das legislações municipais pertinentes; demonstrando o perfil atual do município de Ribeirão Preto no tocante as questões da Gestão Ambiental e Sustentabilidade.

\section{CONSIDERAÇÕES FINAIS}

No município de Ribeirão Preto, assim como nas maiorias das cidades brasileiras, existem vários problemas ambientais que merecem uma atenção maior e 


\section{Periódica Eletrânica \\ Fórum Ambiental}

da Alta Paulista
Volume 11, Número 07, 2015

Politicas Públicas e a Proteção do Meio Ambiente

deveriam ser tratados com mais dedicação e rigor pelos gestores públicos. Entretanto, mesmo existindo uma conscientização ambiental relativamente desenvolvida por parte da população, o município não consegue sair de seus aspectos discursivos para a prática sustentável.

Com base no problema de pesquisa exposto na introdução deste trabalho, pode-se verificar que a criação da Secretaria Municipal de Meio Ambiente, responsável direta por ações ambientais, foi muito recente (2008), considerando-se a envergadura social, política e educacional de uma cidade com mais de 650 mil habitantes, embora exista desde 1993 o COMDEMA e desde 2001 o Código Ambiental. Também mesmo existindo uma manifesta participação representativa da sociedade, o que significa uma ferramenta essencial na criação e condução de políticas públicas ambientais, tais mecanismos foram poucos explorados pelos gestores ao longo das últimas décadas.

Neste estudo, pôde-se verificar que o município de Ribeirão Preto necessita urgentemente da elaboração de um diagnóstico mais preciso e pontual em diversas áreas, estabelecendo reformulações e melhorias em ações já implementadas, assim como de novas ações e avanços em inúmeras outras questões ambientais já especificadas acima, assegurando critérios de gestão sustentáveis e bem estar para a sociedade. Entre essas novas ações, a implantação de um eficiente programa de educação ambiental e conscientização relacionada ao meio ambiente são de fundamental importância, pois o processo educacional é mais perene e irreversível, ao passo que ações corretivas são momentâneas e dispendiosas, embora também sejam válidas dentro do contexto atual.

Basicamente o município de Ribeirão Preto/SP apresenta estruturalmente em seu organograma administrativo, todas as necessidades para um bom desempenho em termos de gestão ambiental, embora na prática tal processo deixe muito a desejar, em função de problemas diversos. Em termos de Gestão Ambiental podemos verificar pelos argumentos expostos que não há uma sintonia entre o Executivo e o Legislativo, e tampouco com os outros órgãos colegiados. Em muitas ações verificamos um Legislativo relativamente submisso, com pouca eficiência fiscalizadora e grande morosidade, ao mesmo tempo em que se verifica uma administração municipal que pouco ouve as recomendações e deliberações dos conselhos afetos as questões ambientais. 


\section{REFERÊNCIAS}

AGENDA 21 - Cúpula da Terra: Conferência das Nações Unidas sobre o Meio Ambiente e Desenvolvimento. Rio de Janeiro, Centro de Informações das Nações Unidas, 1992.

BANUNAS, I. T. Poder de polícia ambiental e o município. Porto Alegre: Sulina, 2003.

BRASIL. Constituição Federal de 1988 (Constituição Federal, Ato das Disposições Constitucionais Transitórias, Emendas Constitucionais de Revisão e Emendas Constitucionais). Brasília: Senado Federal, Secretaria-Geral da Mesa, 2001.

BRASIL. Lei $n^{\circ} 6.766$, de 19 de Dezembro de 1979. Dispõe sobre o Parcelamento do Solo Urbano e dá outras Providências. 1979.

BRASIL. Lei № 12.587, de 3 de Janeiro de 2012. Institui as diretrizes da Política Nacional de Mobilidade Urbana; e dá outras providências. 2012.

CARVALHO, P. F.; BRAGA, R. Perspectiva de gestão ambiental em cidades médias. Rio Claro: LPMUNESP, 2001. $265 \mathrm{p}$.

CARVALHO, P. G. M.; OLIVEIRA, S. M. M. C.; BARCELLOS, F. C., ASSIS, J. M. Gestão Local e Meio Ambiente. Ambiente \& Sociedade - v. 8, n. 1, 2005.

CONAMA. Conselho Nacional do Meio Ambiente. Resolução no 237, de 19 de Dezembro de 1997, Dispõe sobre a revisão e complementação dos procedimentos e critérios utilizados para o licenciamento ambiental. Disponível em: <http://www.mma.gov.br/port/conama/res/res97/res23797.html> Acesso em 23 out. 2014.

DIAS, R. Gestão Ambiental: Responsabilidade Social e Sustentabilidade. 1a. Ed. 4ª . Reimpr. São Paulo: Atlas, 2009.

GONÇALVES, M. F. R. Manual do prefeito. Coordenação técnica. - 13 ed. Rio de Janeiro: IBAM, 2009. IBGE. Instituto Brasileiro de Geografia e Estatística. Perfil dos municípios brasileiros. Brasil: 2009. Disponível em:

<http://www.ibge.gov.br/> Acesso em 05 nov. 2014.

IBGE. Instituto Brasileiro de Geografia e Estatística - Perfil dos Municípios Brasileiros - 2009. (Pesquisa de Informações Básicas Municipais). MPOG. Diretoria de Pesquisas - Coordenação de População e Indicadores Sociais. 2010. 472 p.

IBGE. Instituto Brasileiro de Geografia e Estatística - Cidades@. Informações completas. 2014. Disponível em:

$<$ http://cidades.ibge.gov.br/xtras/perfil.php?lang=\&codmun=354340\&search=\|linfográficos:informações-completas > Acesso em 05 nov. 2014.

INEPAD - Instituto de Ensino e Pesquisa em Administração. Ribeirão Preto e Região: um lugar de destaque no mundo. Centro de Pesquisas do INEPAD. Convention \& Visitors Bureau, 2013. Disponível em:

<http://www.ribeiraopretoconvention.org.br/artigos/ribeirao-preto-e-regiao-um-lugar-no-mundo/> Acesso em 05 nov. 2014.

LITTLE, P. E. (organizador). Política Ambiental no Brasil. Brasília: editora IIEB, 2003.

MAGLIO, I. C. A descentralização da gestão ambiental no Brasil: o papel dos órgãos estaduais e as relações com o poder local, 1900/1999. 2000. Dissertação (Mestrado em Saúde Pública) - Faculdade de Saúde Pública da Universidade de São Paulo, São Paulo. 
MATTEI, J. F.; AMORIM, L. L. S.; LIEDKE, M. S. Trânsito Urbano: O limiar do caos? Políticas de gestão e mobilidade urbana. In: LUNELLI, C. A. (coord.) Direito, Ambiente e Políticas Públicas. Curitiba: Juruá, 2010.

MDIC - Ministério do Desenvolvimento, Indústria e Comércio Exterior. Anuário Estatístico da Secretaria do Desenvolvimento da Produção. Disponível em: <http://www.mdic.gov.br/sitio/interna/interna.php?area=2\&menu=3557> Acesso em 05 nov. 2014.

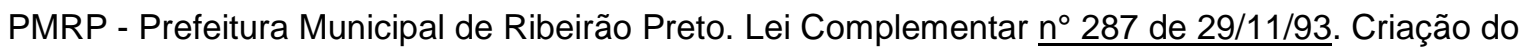
Conselho Municipal de Defesa do Meio Ambiente - COMDEMA, 1993.

PMRP. Lei Complementar no 501, de 31/10/95. Dispõe sobre a instituição do Plano Diretor do município de Ribeirão Preto, e dá outras providências. 1995.

PMRP. Projeto de Lei no 895/98. Cria o Programa Agenda 21 no âmbito de Ribeirão Preto/SP e dá outras providências. 1998. Disponível em:

http://www.ribeiraopreto.sp.gov.br/J321/pesquisa.xhtml?lei=3829 Acesso em 17 de nov. 2014.

PMRP - Prefeitura Municipal de Ribeirão Preto, Câmara Municipal de Ribeirão Preto. Projeto de Lei Complementar nº 181/2001. Criação do Código de Meio Ambiente, 2001.

PMRP - Prefeitura Municipal de Ribeirão Preto. Lei 2.257/2008. Criação da Secretaria do Meio Ambiente. 2008.

PMRP - Prefeitura Municipal de Ribeirão Preto. Lei Orgânica do Município de Ribeirão Preto. (atualizada até a emenda nº 01, de 26 de abril de 2013), 2013.

PMRP - Prefeitura Municipal de Ribeirão Preto. Dados econômicos. 2014a. Disponível em: <http://www.ribeiraopreto.sp.gov.br/crp/dados/i01principal.htm> Acesso em 15 nov. 2014.

PMRP - Prefeitura Municipal de Ribeirão Preto. Parques Municipais Públicos. 2014b. Disponível em: <http://www.ribeiraopreto.sp.gov.br/smambiente/servicos/i22agendamentopp.php > Acessao em 05 nov. 2014.

RIBEIRO, M. A; BRUSCHI, D. M; FRANCO, R. M; PEIXOTO, M. C. D; SANTOS, R. C. Manual de saneamento e proteção ambiental para apoio aos municípios: Município e Meio Ambiente (vol.1). Belo Horizonte: Fundação Estadual do Meio Ambiente - FEAM, 1998.

RODRIGUES, M. L.; MALHEIROS, T. F.; FERNANDES, V. A Percepção Ambiental Como Instrumento de Apoio na Gestão e na Formulação de Políticas Públicas Ambientais. Saúde Soc. São Paulo, v.21, supl.3, p.96-110, 2012.

ROSSETTO, A. M.; ORTH, D. M.; ROSSETTO, C. R.. Gestão Ambiental Integrada ao Desenvolvimento Sustentável. Revista de Administração Pública. Rio de Janeiro, v.40, n.5, p.809840, 2006.

SÃO PAULO. Decreto Estadual n 39.116, de 08-12-98, cria o Comitê de Gerenciamento da Bacia Hidrográfica do Rio Pardo - Comitê Pardo - integrante do Sistema Estadual de Recursos Hídricos. 1996.

SCHENINI, P. C.; NASCIMENTO, D. T. Gestão Pública Sustentável. Revista de Ciências da Administração - v. 4, n. 08. 2002. 